\title{
IDENTITY AND THE CONTROVERSIAL EXPERIENCES OF MUSEUM RESEARCHERS: THE CASE OF THE NATIONAL MUSEUMS OF FINLAND AND THE BALTIC STATES
}

\author{
JANA REIDLA \\ Junior Research Fellow \\ Department of Ethnology \\ University of Tartu \\ Ülikooli 16, 51003 Tartu, Estonia \\ e-mail: jana.reidla@ut.ee
}

\begin{abstract}
This paper* highlights the internal contradictions of museum institutions when they are influenced by neoliberal market-driven policies and new museology from the viewpoint of the museum-working researcher. Museums increasingly interface with the public because they are now part of the leisure market. Recent transformations have affected the roles and responsibilities of museum researchers. Whereas marketing, communication and sales specialists have gained more prominence in museum decision-making, the researchers' role has been marginalised. Semistructured interviews at five national museums in Finland and the Baltic States give voice to museum researchers and reveal their subjective reflections. The interviews revealed two discursive patterns: 1) caring for museum collections is more of a priority than conducting research, and 2) if academic results are prioritised, researchers are less involved in servicing the collections. The analysis showed how perceived marginalisation has caused role conflict and ambiguity for researchers, and that current shifts reduce researchers' motivation to contribute to research.
\end{abstract}

KEYWORDS: researcher $\bullet$ curator $\bullet$ museum $\bullet$ role conflict $\bullet$ role ambiguity

\section{IN TRODUCTION}

The position of the museum researcher is in crisis. Who are you? Where is museum science going? Is this a pure science or do you need to popularise it more and more? (FM: ENM E).

Since the beginning of this millennium there have been numerous conferences ${ }^{1}$ dedicated to research and scholarship at museums around the world. The main concern of museum-working researchers has been that focus on mediating functions was

* This research was funded by institutional research grant IUT34-32 from the Estonian Ministry of Research and Education. 
pushing other museum activities to the background. From the researchers' point of view: "Whereas exhibitions are booming, the very basis of exhibitions - collecting, preserving and object-based research - is threatened in many museums" (Lehmann-Brauns et al. 2010: 4). In addition to the new museology, museums as institutions have, in recent decades, been influenced by the free market and new public management principles. Neoliberal regulations have driven cultural and research institutions towards application efficiency and economic benefit (Griffin and Abraham 2000; Olssen and Peters 2005; Osborne 2006; Thomson et al. 2014). Anwar Tlili (2014) studies professions and organizations and argues that the implementation of a new management policy in British museums has produced unintended consequences in that public-oriented work has overshadowed other working areas. Whereas museums focus on the entertainment side of programs and exhibitions to gain higher visitor numbers, research is awarded scant attention and resource. Much of museum leaders' care is focused on audience involvement, management development, funding and information technology (see Anderson 2005; Graham 2005).

Museum studies highlights the diversification of the curator's profession in terms of directing museum activities to the needs of the audience (Edwards 2007; Nielsen 2014; 2015; Jensen 2019), but the changes in their role and tasks are often seen as inevitable, ignoring the consequences of this shift on the person's self-esteem and work motivation. Management researcher Pascal Ughetto (2017: 378) claims that museum curators have been and are still accused of being remote from the interests of museum visitors, although the priorities of curators are postulated without sufficient research into their working process. Recently a special issue of Museum and Society urged research into organisational settings and museum practice in order to initiate a debate on "the finer details of practices and the varied conditions in which they take place" (Morse et al. 2018: 113), arguing that museum studies have focused more on representative and interpretive topics than on the work of museums. In addition, as has been suggested, "informal relations, uncodified activities, chance events and feelings" (Macdonald et al. 2018: 138) are often overlooked in museum work studies.

This paper provides empirical analysis of the changing identities of museum researchers in the Baltic States and Finland. The point of departure is in discussions on the challenges neoliberalist policies pose to the profession of museum researchers in the Estonian context, ${ }^{2}$ which was compared with three neighbouring countries, Finland, Latvia and Lithuania. The study aims to expand the knowledge of how researchers perceive their identity and interpret their tasks in today's museum in each region. A wider regional insight should enable references to further research into museum professionals. In order to understand what hinders the performance of researchers, how they align or not with the changed goals of the institution, answers were sought to the following questions: How is museum-based research conceptualised by researchers, and how do they perceive the roles of mediator and expert in particular? What expectations are placed on researchers' personal qualities and skills, and how have they adapted to them?

The analysis highlights how internal contradictions arise in museum institutions through the influence of neoliberal market-driven policies and the ideas of new museology. The discourse of new museology on the socially relevant museum is neither incomprehensible nor disagreeable to researchers, although they do feel their potential 
for research is undervalued within such institutions. This study provides a point of departure to explore how researchers need institutional understanding and support, thus enabling the two approaches to move closer to each other.

\section{METHOD}

Studies of museum researchers' experiences of their work slots into the fields of museology and organisational anthropology. Organisation scholar Barbara Czarniawska (2012: 127) states that ethnography was the dominant method in organisation studies in the 2010s. To research museums as 'peopled organisations' the museologists Nuala Morse, Rex Bethany and Sarah H. Richardson (2018: 115-116) advocate interpretative methods (for example phenomenological, hermeneutical) to capture professional meaning-making as the focus of research. Methodologically, this study is based on the idea of "peopled organizations" which emphasise the role of museum staff in "actively producing and resisting the museum" (ibid.: 116). The 'lived experiences' of the interviewees are not seen as data, but as personal experiences that need to be understood and explained via interpretative narrative analysis.

This study is based on 34 semi-structured interviews conducted with professionals from the national museums of Finland and the Baltic States between November 2016 and February 2019. The study involved five museums: 1) the Estonian National Museum (ENM; Eesti Rahva Muuseum), 2) the Estonian History Museum (EHM; Eesti Ajaloomuuseum), 3) the National History Museum of Latvia (NHML; Latvijas Nacionālais Vèstures Muzejs), 4) the National Museum of Lithuania (NML; Lietuvos Nacionalinis Muziejus), and 5) the National Museum of Finland (NMF; Suomen Kansallismuseo). These five museums are situated in a cluster of four neighbouring countries running along a north-south axis on the eastern coast of the Baltic Sea. All the museums were stateowned during the fieldwork and functioned as central museums of cultural history, each dedicated to the history of its country and people.

During the fieldwork, all five museums were visited at least twice, and some of the professionals were also interviewed a second time. The interviews reflected the wide range of tasks that a researcher working in the museum could perform, from caring for collections to research and mediation. Of the interviewees, 25 were researchers, ${ }^{3}$ of whom three were also managers. In the countries under study research staff's job titles are varied: 'curator', 'researcher', 'researcher-curator', 'museum professional' (see Reidla 2018). The term 'curator' usually has the narrow focus of exhibition maker, and therefore the term 'researcher' is used in this paper as a generic denominator to professionals with a research capacity. In addition, nine administrative professionals in the fields of collections, exhibitions and communication reflect on their expectations of the researcher's personal qualities and skills. The sample of interviewees was not designed according to age or work experience, but most of the interviewees had long experience of working in museums. ${ }^{4}$ Therefore, no conclusions have been drawn based on the age of the interviewees or the length of service except that most of the interviewees have experienced shifts that characterise the 21st-century museum.

Identity is understood in this study as a developmental learning process involving emotions (Geijsel and Meijers 2005) that is constructed and negotiated in social interac- 
tion (see for example Saayman and Crafford 2011; Ylijoki and Ursin 2013). As people have various roles within their identities and relationships, they are permanently negotiating their identities by defining the self in relation to others. This negotiating "most often involves resolving tensions between personal and social identities" (Saayman and Crafford 2011: 2). Sociologists Femke Geijsel and Frans Meijers (2005: 424) explain that "identity learning starts with an experience in which the individual experiences the boundary of the existing self-concept". The process is quite problematic due to the frequency of conflict and the insecurity of individual experience. In such situations a person initially feels existential insecurity that he or she perceivs as unacceptable, and therefore that individual seeks to restore a sense of well-being. However, to rebuild the balance between 'identity configuration' and the altered situation, the individual must enter an existing discourse, which Geijsel and Meijers (2005: 425) call discursive meaning-giving. In this process, the individual tries to find concepts that provide an explanation that is logically and emotionally satisfactory for all involved in the dialogue. Geijsel and Meijers (ibid.) emphasise that, "Understanding a situation is not enough: the situation must make personal (emotional) sense for the individual, so that he or she is motivated and able to act." In the best case, this process results in mutual understanding and common values. If a change of professional role is not prepared, tensions and insecurities will ensue among employees, as Jennie Billot (2010) explains.

Controversial experiences that emerge from the interviews will be analysed through the concepts of role conflict and role ambiguity. According to the role theory used in organisational studies (Kahn et al. 1964; Wickham and Parker 2007; Schmidt et al. 2014; Campbell 2018), role conflict and role ambiguity can lead to employee depression, demotivation, and reduced workloads (Schmidt et al. 2014: 92). The concept of role conflict has been defined as the simultaneous occurrence of two or more incompatible expectations in a person's behaviour, in which the person who is the subject of conflicting pressures is unable to meet the different demands simultaneously. Role ambiguity arises when a person in a certain position becomes insecure about his or her expected way of performing a role, as well as about the goals and responsibilities of the job, due to a lack of information. (Kahn et al. 1964; Schmidt et al. 2014; Campbell 2018)

The museums studied do not form a homogeneous group. Different types of organisation structure are represented, as a result of which there are variations in the production of exhibitions and the management of collections, communication and research (Reidla 2018). The analysis will focus on three key topics, which emerged from the interviews linking the role and identity of the researcher. First, the researchers' conflicting views on collection-based research and academic research, combined with distinctions in rhetoric and the practice that influence researchers' understanding of their role. The second involves researchers' activities as content experts and consultants, representing the museums in communication with various stakeholders. The third concerns the salience of the relationship between the popularisation of museum work and academic research in the context of the museum. To illustrate the findings of the study, some examples of interviewees' expressions are given, although similar views were expressed by several. This study intentionally gives voice to museum researchers so that they can reveal their subjective reflections. The opinions of administrators are not presented, except where expectations of researchers' skills are reflected. 
The author's experience working in Estonian museums means many of the interviewees are former colleagues, something that will have influenced the results. ${ }^{5}$ Thus, interviews conducted at the ENM and the EHM are somewhat more open and emotional compared with the others. Analysis is likely to be influenced by the fact that author is much more familiar with the history and cultural-political background of Estonian museums than with comparable museums. It is presumed that some of the researchers' problems or motives remain unrevealed, especially in Latvia, Lithuania and Finland, because the author was not previously familiar with them. Identity issues are related to emotions that are not easily expressed, nor are opinions that run contrary to the mainstream expressed so easily to strangers.

Despite regional peculiarities, the information field of Baltic museums is influenced by the same factors as in the rest of the world: new museology, market economy, neoliberal cultural and education policy, new management approach in the public sector. Thus, to provide a context for this study, I will provide a literature-based global overview of museum research, which is largely of UK, Canadian and US origin.

\section{RESEARCH AND THE RESEARCHER IN THE MUSEUM}

This section provides not only a brief overview of the position of research in the museum and recent shifts in the field, but also contributes to the discussion of whether and how research in the museum differs from academic science. In order to set a framework, it is also necessary to clarify somewhat fluid concepts such as research in museums, objectbased research, and both the museum researcher and the curator.

Although most museums are not science institutions, research has traditionally been considered one of the main functions of museums, alongside the preservation of collections and their mediation (Desvallées and Mairesse 2010: 73). The 19th-century museum differed from earlier curiosity cabinets and entertainment fairs precisely because of its scientific and systematizing approach (Bennett 1995). At the end of the 20th century, museums began to move away from their scientific expert role to the role of mediating science (Macdonald 1998: 13). Concurrently museums began gradually to become part of the leisure industry (Foley and McPherson 2000; McPherson 2006). Since the beginning of the new millennium, the balance between museum functions has changed. Social relevance and mediation activities are at the forefront of the museum's activities, while research has been included in the service of outreach. Museum managers have focused on funding, audience involvement, building management and information technology, and not on research.

\section{The Curator as Museum-Working Researcher}

The museum-working researcher's position in English-speaking countries is often called curator. In the current analysis, the concept of the museum-working researcher is based on descriptions of curatorial work in UK and US job portals (Doyle 2019; TargetJobs 2019), in the Handbook for Museums (Edson and Dean 1996) and in the document compiled by the ICOM International Committee for the Training of Personnel (Ruge 2008). 
According to these sources, a curator is a collection specialist who acquires, describes and documents collections, handles loans, responds to information requests and interprets collections through exhibitions, publications and audio-visual presentations. A curator also studies the collections, defines and conducts research projects, and gives lectures. All of these tasks require curators to work with colleagues in conservation, education, design and marketing. The requisite education is a master's degree in a discipline corresponding to the museum's collections (Ruge 2008: 16), although students who have not yet completed their degrees find work as assistant curators (Doyle 2019) enabling them to gain valuable work experience in the field. Becoming a lead curator at a major museum requires both a $\mathrm{PhD}$ and at least five years of field experience (ibid.). Thus, the concept of curator can be equated to the concept of museum-working researcher.

As British sociologist Vikki McCall and cultural policy researcher Clive Gray (2014: 24) note, new museology has moved curators away from their traditional role of providing the intellectual foundation for work within the sector. According to museum researchers operating in the leisure market, museums have drifted away from the principle that "museum research is based upon the collection, and museum programming activities grow out of the research work" (Reid and Naylor 2005: 360). This trend is also indicated by quantitative studies (Edwards 2007; Jensen 2019) that acknowledge the museum has seen concessions to the demands of academic skills, with an emphasis on communicative and administrative skills and the corresponding personal qualities. These shifts demonstrate how museums became not only community-oriented but also more market-oriented in the 2000s.

Within traditional museum discourse, working with collections is considered a privilege because collections are valued as the heart of the museum. Historian of science Samuel Alberti (2012) describes curators in the middle of the 19th century as being connected so closely with the objects under their care that the object of research, i.e. the collection, began to define the curator's identity and authority. According to a recent study, by cultural geographers Hillary Geoghegan and Alison Hess (2015), of the London Science Museum, professionals working within collections still have emotional relationships with their objects. Because the discourse of new museology questions collections as a reason for the existence of a museum (see for example Vergo 1989; Weil 1999), an emotional attachment to collections is not always assessed positively. Indeed, it has been seen as a constraint on the openness of museums. ${ }^{6}$ This controversial approach has become a challenge to object-based research and researchers.

\section{Object-Based Research}

As with science institutions, larger museums publish research, organise conferences and hire researchers. Traditionally, museums are distinguished from other science institutions by their areas of research with the museum environment essentially supporting object-based research. Description and classification are traditional curator's duties that keep collections available, although original research often also includes the description and systematisation of objects, ${ }^{7}$ especially in some disciplines. Consequently, the scientific description of artefacts is a preliminary work for subsequent research. 
Today, object-based research is no longer self-evident within museums: digital collections are expanding rapidly, the profile of museums has diversified, researchers are turning to newer research topics and methods. The incompatibility of research topics assigned to artefacts within new museology is not a minor factor, as socially relevant topics are not necessarily presented through objects. Rather the objects have been studied as part of broader cultural processes. Collecting contemporary material no longer focuses so directly on collecting objects but rather on recording present day life - as the Swedish museum network Samdok has proven since 1977 (see for example Fägerborg 2006). More recently, research has focused on examining the formation of collections (Greene 2015: 2), which provides the necessary context for the research of museum collections. Critics argue that there has been too little anthropological study of museums despite Steven Conn's (2010: 79) assertion "the anthropological study of the museum" prevails.

Withdrawing interest from the collections has resulted in a reduction of experts in collections (Greene 2015: 7-8). In response to the loss of interest in collections, British anthropologist Nicholas Thomas (2016: 141-142) considers it important to intertwine different aspects of the curator's work because "research, exhibition and public engagement ought to be in dialogue but they cannot be if curators are no longer researchers, or if research curators are disconnected from collections, displays, events and educational programmes". Data based on archives, photographs and literature, as well as experimental methods are used in object research. For historian and former curator Adrienne Hood (2009), describing an object is as important a tool for obtaining information as studying archival documents and literature or gathering data on the formation of a collection. Hood (2009: 302-304) advocates a sensory approach to objects: touch, smell and listen, and even try to use it.

To emphasise the special nature of museum science, Thomas $(2010 ; 2016)$ proposes the idea of collection-based museum work as a specific method. Thomas (2010: 7) claims the "museum as a method" is specific due to the unpredictability and multilayered nature of collection-based artefact research, characterised by the keywords "the discovery, the caption, and the juxtaposition". Although the object researcher benefits from manual skills and knowledge of materials, it is important to combine technical skills with academic research methods in research. It is necessary for a researcher to critically evaluate the descriptions in the database as they could be misleading, and understanding interpretation requires knowledge of comparable objects. Thus, objectbased research emerges here as one of the subfields of material culture studies. Objectbased research does not narrowly focus on objects as a source of research. The modern approach requires the inclusion of new perspectives and new information, which allows us to see and interpret 'old' objects from new perspectives.

\section{Communication and Other New Shifts}

Curator of ancient art Peter Schertz (2015) argues that collection-based research distinguishes museum researchers from academic researchers, highlighting curators' active communication with the public. According to the commonly held view, exhibitions are the main platform for museum-based researchers to communicate with the audience. 
For curators the exhibition is one mode to publish research, which they want to be addressed in the same way by academics (Brüning 2010; Hauser 2010; Schnalke 2010; Schertz 2015). Curators acknowledge that in spite of their request, the making of exhibitions is not considered an important academic achievement, with only the catalogue considered a work of scholarship (Schnalke 2010; Schertz 2015). Paradoxically, the success of museums in communicating research results to the public through exhibitions and digital media is given as an example for academics (Clifton-Ross et al. 2019).

In the discourse of the new museum, research is important primarily to provide input for museum education and popularisation, as indicated by ICOM publications (Ladkin 2004: 29-30; Desvallées and Mairesse 2010: 57, 74). Furthermore, the Key Concepts of Museology (Desvallées and Mairesse 2010: 74) states the importance of economic effects: "Aided by market mechanisms which have favoured temporary exhibitions to the detriment of permanent ones, part of the fundamental research has been replaced by a more applied research, particularly in the preparation of temporary exhibitions". The consideration of the results of academic research in the evaluation of the performance of the museum has decreased in government policies; instead the numbers of visitors, web visits, programs, etc., became important indicators in the 2000s (see about UK case Anderson 2005: 301).

To formulate new constructive potentials for museum-based research, new outputs have been proposed in the form of specific methodologies that combine academic and artistic research (see Arnold 2016; Bjerregaard 2019). Recently anthropologist and museologist Peter Bjerregaard (2019) introduced the concept of 'exhibition as research'. Instead of considering the exhibition as a platform for the transmission of previously generated knowledge, Bjerregaard advocates the exhibition as a knowledge-generating process. This means that museum researchers can collaborate with professionals from different disciplinary backgrounds outside the museum, as well as involving nonresearchers in research issues. This method does not oppose either new museology or collections but seeks to integrate research and museum collections into a framework for public engagement.

In summary, research in museums is comparable to the academic version in terms of possibilities. However, the nature of the museum directs researchers to the mission of researching collections and presents them as experts. Recently, there has been an increased effort to involve the audience in the understanding of collections. The most common form of interpreting collections and communicating with the public is the exhibition, although curators have so far failed to present an equivalent to academic research. Researchers working in museums consistently emphasised the special nature of museum science, both in terms of method and object of research. However, such a distinction is conditional, since objectively researchers, both internal and external, can use museum objects as sources, publish research in scientific journals and curate exhibitions.

The following section provides an analysis of how museum-based research is conceptualised by researchers from national museums in the Baltic States and Finland. All museums under study are managed by the relevant Ministry of Culture. The focus of the empirical data is on the researchers' lived experiences, which reveal the contradictory discourses of museum-based research from their point of view. 


\section{CONTRADICTORY DISCOURSES OF \\ COLLECTION-BASED RESEARCH}

Most of the interviewees found that the study of collections distinguishes museums from academic institutions. Differences between museums reflected how museum professionals' need to research their collections relate to their perceived institutional practices. Two conditional discursive patterns emerged from the interviews: 1 ) if a researcher's tasks are closely linked to mediation of collections, the researcher is frustrated that science is not a priority for the institution; 2 ) if a researcher feels that the institution prioritises academic results without emphasising expertise in collections, the researcher's relationship with the collections becomes distant. In both discourses, the researcher feels both role conflict and ambivalence, as it is difficult to reconcile the researcher's self-identity with what the institution values.

\section{Collections as a Priority}

Researchers working with the collections at the EHM and the NMF said in their experience the priority of their work was to provide access to collections, to encourage their use by the public, but not to personally study them. The NML, with certain caveats, also falls into this group, although caring for the collections was the priority as opposed to making them more accessible. As these three museums do not form a homogeneous group, both their commonalities and some specific features will be highlighted.

In these museums, the tasks of research-level employees are closer to the position of collection keeper than researcher. Interviewees believed it necessary to maintain an emotional connection with artefacts, linking this belief to the identity of museum professional. In the case of Finland, a recent study by Inkeri Hakamies (2017) also shows that employees consider a close relationship with collections to be an important feature of the museum professional. It appeared that NML and EHM staff have a similar opinion. A personal relationship with the collection was emphasised: "If you work in a museum you are already a spoiled person, each item seems necessary, you want to collect everything" (FM: NML A). Referring to the specific nature of the museum institution compared to a university, one interviewee said, "Otherwise, it doesn't matter where you are a researcher, you can say: 'Goodbye, I'm going to the next place now!' at any time. I think this [being a collection manager] is very important emotionally, it's a direct relationship with history." (FM: EHM C)

A second common feature was the declining role of academic research in museums. Research had, in the opinion of many interviewees, lost ground in their work compared to previous decades. A distinction was made between descriptive 'research on collections', and academic research, which results in monographs or articles. Research on collections of previously collected material will occasionally be reactivated when new exhibitions are made (FM: NML A; NMF B; NMF C). According to researchers there is no institutional obligation for academic research: "[...] if you have the will and initiative, you can also do research. The history museum in particular does not need or boost science at the moment, it is not a priority, rather the field of curation is [a priority]." (FM: EHM D) 
The [researcher's] main task is to manage collections, keep a register, and physically review a specific collection. Other tasks include preparing exhibitions and writing scientific articles, although this largely depends on whether the employee has a corresponding interest in it. We belong to the Ministry of Culture, but the research is administered by another ministry. What we do is culture, but research is not obligatory. (FM: NML C)

One internationally recognised researcher stated ironically: "Nobody forces us [to perform research], but fortunately no one really forbids it either" (FM: EHM C). Academic research has become an individual preference driven by personal ambition: alternative ways of publishing are sought and participation in university-led projects is preferred. Museum staff cannot apply for a grant alone because they do not work in a research institution. The insignificance of academic research was often justified by the museum's status as culture institution (FM: EHM D; EHM E; NML B; NML C). Many researchers, especially those working at the SKM, complained about the lack of time that additional administrative and popularisation tasks cause, while at the same time the number of staff had been reduced over the last two decades:

We have three ethnologists in the ethnology collections. About 20 years ago, there were 20 ethnologists in our unit. That's why we don't have much time to do science. [...] I would like to do research on a daily basis, but I can't. I could be a researcher by education, but I have to do all sorts of other things. (FM: NMF C)

Moreover, instead of researching, curators have to serve those university researchers or other 'clients' who are interested in the collections. In addition to tasks relating to the collections database, lending artefacts, and serving visitors, the NMF curators highlighted the obligation to provide information on social media as disrupting research. The archetypal curator who is less concerned about providing access to collections was a specific feature of Lithuania's national museum. The NML focuses on the traditional publishing of collections, and not on digitisation. Although collections-centred research at the NML seems to exist organically among the curators' tasks, the rhetoric of the NML staff complaining about the low status of research in a cultural institution was similar to the rhetoric issuing from both the EHM and SKM.

Whereas the interviews reflect the lack of time, uncertainty and confusion perceived by the research staff, the key issue seems to be an imbalance in the distribution of financial and human resources, which is affected by government museum policy and is the responsibility of museum management. The interviewees noted that none of the countries' Ministries of Culture payed any attention to scientific work in performance measurement. Instead, the core values are the numbers of artefacts input to the database, and visitor numbers. One reason for this is the museum policy goal of making collections accessible through digitisation. Quantitative measurements of this are generally relevant, but also have weaknesses, especially if used without qualitative measurements, because this will lead to a reduction in the time-consuming activity of scientific description of artefacts. Thus, the prevalence of quantitative metrics does not encourage the museum to focus on research.

In academic discourse self-realisation and in-depth collection research are shadowed by collection service duties. Differences within the discourse are found at the NML, which assists collection-centred research, whereas the EHM and NMF both sup- 
ported collection mediation over research. Museum professionals perceive research as being undervalued, because it is not funded, there is a lack of any requirement to perform research and Ministries of Culture lack even evaluation criteria. Thus, staff often consider research an optional self-realisation activity. However, while some research curators at the EHM carried out research, their peers at the NMF have only nostalgic memories of research.

\section{Emphasis on Academic Research}

The discourse emphasising academic research emerges primarily from the opinions of ENM researchers, although its characteristic features were noticeable at the NHML. In these museums, management encourages researchers to realise themselves as academic scholars by directing them to compete in the field of international academia. The core point of this discourse is that researchers are involved in the care and service of the collections much less because their priority is academic results. In addition, the institution expects them to act as knowledge experts and curators of exhibitions.

While ENM researchers have not performed the functions of collection keeper for decades, the specialisation of NHML staff as keepers and researchers has only come about in recent years. Such an informal specialisation was justified due to the desire to ensure the quality of both research and an audience interface: "A few years ago we had more researchers and they were all involved in collection care, and it was also wrong, because their priority then was collections and not the needs of society and the public" (FM: NHML D).

This way in which the caring and servicing of collections as one of the museum's basic functions contrasts with the idea of a social museum that meets the needs of society is intriguing. Perhaps it should not be seen as a paradigmatic conflict within the museum as an institution, but as a pragmatic working arrangement? Such an organisation of work indicates an attempt to solve a problem that arose when staff did not find time for research because of the need to care for the collections. A side effect of specialisation is the expansion of research topics beyond collections, as researchers are not tied to dealing with specific materials. Exhibitions are still curated by researchers at the NHML, and for sustainability, research into collections is delegated to keepers who have competence in the respective discipline.

According to the ERM's website, the museum's research activities are linked "to the interpretation and communication of knowledge related to cultural heritage collections" (ENM a). Recently ERM's collections have received the attention of researchers through exhibitions ${ }^{8}$ and one-off research projects. ${ }^{9}$ However, answers to the question "how does research in your museum link to collections?", confirmed that the link is vague: collections are rather not in any plans as objects of research (FM: ENM E; ENM F; ENM J). Interviewees confirmed that the idea of researchers preferring to ignore objects as sources is accepted at the ENM. One researcher (FM: ENM J) used the statement: "because I am not a things person at all" (FM: ENM J) to justify this choice.

There seemed to be concern that sporadic research into the collections has led to a critical decline of knowledge about artefacts preserved at the ENM (FM: ENM A; ENM E; ENM G). The experienced researchers generally equated collection-based research 
to the museum researcher's identity, even if they had no obligation to research the collections. They would like to commit to the collections more if this did not conflict with the management's ambition for higher academic output. The conclusion is that research based on the collections is not a priority at the ENM. ${ }^{10}$

Alone amongst the studied museums, the ENM gives the freedom of choice to staff on topics to research, unlike the NHML, where researchers (FM: NHML C; NHML D) confirmed they must take into account the museum's perspective when choosing research topics. New employees at the ENM often continue to develop their original research topics, which do not have to be linked to the museum's aims. Ultimately these topics have shaped the museum's research directions. Critics of this trend suggest the museum's research goals have been set too randomly (FM: ENM E; ENM F). Yet another difference between the two museums is that at the NHML, the collection keepers also conduct research, whereas at the ENM they are assigned technical work, and not research.

ENM researchers acknowledged that the head of department values their ability to publish articles in internationally recognised scientific journals, attend conferences abroad, and maintain international research connections. Interviews revealed that valuing academic achievement and encouraging competition between individuals sometimes takes the form of pressure (FM: ENM B; ENM E; ENM F; ENM I). Pressure has manifested itself, for example, in the analysis of publication metrics at research department meetings in a way that creates a sense of inferiority among researchers with poorer academic results. International competitiveness is so important to the ENM compared to other museums because it is the only one that is certified as a research institution. Therefore, the ENM is influenced by the same neoliberal research policies as academic research institutions. Because of its inherent instability the project-based nature of research funding has created uncertainty about the future among researchers. Nor do projects guarantee the continuity of collections research or long-term planning.

To summarise, in a discourse that prioritises academic performance, there is a presumption that collection-based research does not provide the potential to compete in the international arena. In this discourse, museum researchers have concluded that they should not devote time to researching collections or to organising the database, as management only appreciates their 'scientific productivity'. The decline in research on collections (including both description and scientific generalisation) exists in both discourses. While in the first of the two discourses, researchers felt that they were mainly in the service of the collections and their personal research potential remained unused, in the second they were interpreters of collections through exhibitions, although their research topics spread beyond the collections. Consequently, their relationship with the collections is ambivalent. On the one hand, there is a perceived danger that collections will be neglected if they are not studied by staff researchers. On the other hand, integrating the new museology and new public management concepts has added strength to the focus on promoting the use-value of collections. However, providing online access to collections without advancing any proper research on them is probably not a sufficient solution to ensure the usability of collections. 
Although the decrease in collection competence was discussed self-critically in both discourses, the function of the collection-based expert was represented in all five museums. According to the paradigm of an actively communicating museum, the museum researcher has inevitably had to become an expert in mediating the museum and public speaking. How researchers understand their roles as mediators and experts, what expectations have been placed on them, and how they have adapted to this, is examined below.

\section{Promotion of Collections and Exhibitions}

The appeal of museums to the public has included not only the emphasis of exhibitions and entertainment/educational programs, but also the better accessibility and usability of collections (see Glaister and Wilkinson 2005; Keene 2005; Cross and Wilkinson 2007). There are many possibilities for the promotion of collections (see Keene 2008; Matassa 2010) that are not addressed here. The most vital part of making collections available entering data into an electronic system - was discussed in the previous section (see also Reidla 2018). This section deals with researchers as content experts and popularisers and shows what it means in terms of their self-identity and the demands placed on them.

Several interviewees (FM: EHM C; EHM F; NHML D; NMF B; NMF D) emphasised that promotions are an important feature that distinguishes museum researchers from academics. The NMF stands out here because curators with researcher competence manage the museum's social media accounts that relate to the collections:

When you ask me if I see differences in museum and university research, I only see differences. The reason for this is the strategic goal of our museum, our aim is to open the collections as much as possible, to make them available to users, this is the number one priority. [...] Facebook, Instagram, Twitter. One or two or three times a week we do something there. (FM: NMF D)

Although marketing, sales and public relations specialists make initial contacts in order to promote collections and exhibitions, the researchers' contribution is essential in compiling information as well as in mediation. Even if the technical work is left to the communication specialist, the creation of texts to promote the collections and make them accessible is largely a matter for researchers because they are competent in composing professional information: "The marketing manager is reliable and active, but since she does not know the content, in many cases I do her job myself" (FM: ENM F).

The interviews (FM: EHM C; ENM F; NHML D; NHML I; NMF B; NMF C) indicate that curators take responsibility and do not shy away from communicating with the media. They rather offer to talk about the exhibition themselves - for the benefit of museum communication "because they know more about the content of the exhibition than public relations and others" (FM: ENM F). This attitude indicates the value researchers carry in terms of the museum's relevance. Expertise outweighs even modest performance skills: "Naturally, researchers and exhibition curators communicate with 
the media, not the exhibition department. We always send a specialist who knows the subject to communicate with the media. A correct and detailed answer is more important than an attractive speech." (FM: NHML D)

Thus, when the significance of promoting collections (and exhibitions) is recognised in the museum, performance of these activities has added to the researchers' responsibilities. According to interviews this shift became apparent especially at the NMF, while it was neglected at the NML. For the NML, the priority was to publish the collections themselves (FM: NML F; NML G), rather than to promote their use.

\section{Consulting}

If promotion is a proactive approach, consulting reflects the stakeholders' demands. The public expects museum professionals to know about their collections, which is indicated by frequent requests for advice and expert opinion (FM: EHM A; EHM C; EHM D; ENM A; ENM B; NHML C; NML A; NML F). People turn to the museum with questions about old objects, documents and photographs, assuming that the museum employs experts in the field. In the expert role, researchers are partners for advertising, heritage protection and education institutions, collectors and craftsmen, artists and filmmakers, as well as for law enforcement agencies.

Electronic communication has made consulting a daily routine in all museums. People ask questions in person less frequently, rather, they write and send pictures more often. Other than its time-consuming nature, the interviewees did not have negative opinions about consulting, even though it has become a daily task. This may be related to the emotional satisfaction that sharing expertise brings while at the same time reinforcing their professional identities. Answering those who ask for advice was perceived primarily as a museum mission: "[because] the museum is a public institution, I have always said that I help those who do not know, or I volunteer to help when someone has been misinformed. [...] So, I identify items or give consultations every second day." (FM: EHM A)

Often consulting takes place on an ad hoc basis, so it is difficult for an expert to determine when to officially formalise the consultation and ask for a fee. Notably in the case of the NML and EHM, charging for the use of collections was not considered important. As a researcher with ten years' experience explains: "Providing an expert opinion is the museum's responsibility, and we have price lists, but in fact I have never provided expertise on the basis of a fee" (FM: EHM D).

Presumably such a practice hastens researchers' understanding that their knowledge does not produce revenue for the museum, although no such reasoning was observed in the interviews. Being an expert was addressed as an important feature that added to the museum's social relevance. Consulting was also called an activity that justifies public funding. It follows, despite the pressures of the market economy, that expertise is considered a mission activity. Although consulting is expected to increase the relevance of the museum to society, it has a low economic and statistical value because it does not significantly increase visitor numbers or revenue. 
From the researchers' point of view, their profession requires them to treat even simple texts and presentations with responsibility, rather than superficially. Therefore, researchers conduct lengthy preliminary work to provide reliable information to the general public. Conflict arises because the preparatory work done for mediation, be it an exhibition, consultation or lecture, often does not qualify as a valuable achievement to management (or to the assessors of the institution). Such a contradiction is considerable in museums that emphasise academic performance, as the ENM does. To a certain extent, all ENM researchers are linked to popularisation. This mainly applies to the curators of the special unit established for cultural heritage mediation, because this is the field of traditional peasant culture that the museum aims to popularise. ENM curators of cultural heritage mediation have studied the collections, but felt that management did not value their contribution to the research department. As noted above, research on peasant culture is not considered competitive in the international research field.

Interviews with the ENM researchers reveal that from their point of view, no balance has been found in the evaluation of work results. As some individuals have better academic output and others are better suited to popularisation, tensions arise because peculiarities are not considered. Ambiguity and conflict in the researcher's identity in the context of popularisation were also expressed in context of exhibition curation: "Whereas articles in a [highly indexed] journal give you something [personal assessment value], five years of making a permanent exhibition, which is also related to research, falls under 'other works' [category 6.7 in the Estonian Research Information System]" (FM: ENM E).

Doubts about employee's priorities arise because publishing articles in highly indexed journals is valued by management, while exhibition-related activities, although research-based, are considered 'creative' and mainly judged by number of visitors. In this way, there is a conflict between the valuation of research (in-house benefit) and mediation (public benefit). Such tension, caused by an underestimation of the value of popularisation, is not reflected in the interviews other than those conducted at the ENM.

\section{Perceived Marginalisation}

As a global trend, museum marketisation and outreach have increased the number of staff involved in those activities. Concomitantly, the research workforce has been a declining resource, resulting in fewer researchers covering a wider range of topics and tasks. With the decline in numbers, the voice of research staff in decision-making has become weaker as different types of administrator have gained more representation at management meetings. A similar trend pointed out by former museum director Robert Anderson (2005: 303) in the British context, was also evident in the Estonian and Finnish museums studied. Interviewees at the NMF stated that the number of researchers has decreased in the last decade, while staff involved with public relations, marketing and museum education have increased (FM: NMF B; NMF D). In contrast, it was noted that 
at the ENM even if the number of researchers was the same, the department felt smaller because "other in-house structures have grown" (FM: ENM F).

Discussing the transformed power relations at museums, British historian and curator Barbara Wood (2019: 22) argues that while there have been legitimate and welcome ambitions to diversify and democratise the function and purpose of museums, this has also resulted in the removal of power from specialist authorities. Such developments, she suggests, may lead to the "jeopardization of the core functions and purpose of the museum" (ibid.: 23). The focus on mediation activities is therefore considered a reflection of the application of market logic in museum work (Jensen 2019: 474). This need to bring in revenue through mediation was also reflected in the interviews conducted for this study (FM: EHM C; EHM F; ENM F; ENM I; NMF E; NML I). An experienced researcher highlighted the connection between publicity and the economic interests of the institution:

In my opinion, the priority now is publicity, to be in the picture as much as possible, to sell as much as possible - the same as everywhere. [...] State funding will not increase, as we know. Outward-looking activities are important. Exhibitions and all kinds of performance. (FM: EHM C)

The researchers of both the EHM and ENM seemed to agree that their boards would make decisions solely on the basis of economic arguments. In the case of Estonia, the researchers expressed the view that as they did not generate internal financial income, they also did not to have any influence over the organisation. Therefore, an important shift in the profession of researcher is perceived marginalisation, which affects the motivation of the researchers.

\section{Favourable Personal Qualities and Skills}

Less than might have been expected, researchers' concern about old objects and documents was emphasized as a necessary personal quality. This characteristic was mainly observed at the NML, where the need for routine tolerance of working with collections was pointed out: those who "do not feel the need to study, describe and read about objects" will not survive at the museum (FM: NML A).

In general, it seems that research staff and managers have reached a consensus: the museum researcher must be an open-minded multi-skilled person with strong communication skills. The head of a department at the NHML described their expectations of a museum researcher as follows:

We need a specialist in a particular science field, we need people who can communicate very well, guide excursions if needed, [...] who can switch between various topics at one year or even shorter intervals. We need people who can write texts and it's also a skill [that not everyone has] that they can write good texts for exhibitions or museum books or something else. (FM: NHML D)

At the EHM there was a significant emphasis on the personal qualities and skills a researcher should have, which public relations and exhibition managers expressed as the ability to curate attractive exhibitions (FM: EHM F; EHM G). In their opinion this 
facet is most important for a museum, and not every researcher is suitable for this type of museum work. Researchers with an ambition to go "chasing details", "dealing with their collections" and "writing books" were considered unsuitable for the curation of exhibitions (FM: EHM F; EHM G). In addition, the roles of the collection keeper and of the exhibition curator were contrasted: "there is a lot of desire to be the one who deals with a collection, but this is a completely different type of person from the one who wants to deal with exhibitions" (FM: EHM G).

Some of the interviewed researchers from the NMF and NHML admitted they should be considering the goals of an open and social museum, and that this requires certain skills (FM: NHML H; NMF B; NMF C). They were content to be flexible and deal with several topics in parallel and switch from one to the other. It follows from these answers that the researchers have accepted their superiors' attitudes, i.e. that this work is not suitable for an introvert. A similar attitude was not evident at the NML, where there has been no shift to prioritise communication, and neither speaking skills nor multitasking were considered part of the researcher's identity.

Although researchers were generally reconciled to the requirement to be flexible, they acknowledged that in-depth research and extensive preparatory work are better suited to their identity. The researchers' confusion because of suddenly increasing demands was reflected quite emotionally:

[I] can't [shoot] from the hip and [make] articles come as from the Ford [assembly] line. [...] When a topic is mentioned, then - what's the matter? You're a person with a degree [the management say], you have to be able to do it right away - wow! (FM: ENM I)

To conclude, most researchers act as experts to abide by the museum's diverse communication requirements, fulfilling this role in both the form of museum-initiated events and in response to appeals from various stakeholders. While researchers in the expert role may increase the social relevance of the museum, mediation activities do not increase their academic relevance. Even if the number of administrators and communication specialists is growing, researchers are also expected to have the appropriate personal qualities and skills. Increasingly, a flexible and extroverted personality type was valued for research staff. Indeed, widespread opposition to communicating with the audience did not exist among research staff. However, frustration and fatigue could be observed, caused by the fragmentation of their activities on several fronts, which prevented them from delving deeper into their research and instead prioritised mediation tasks.

\section{CONCLUSION}

Changes within the museum sector challenge the role and responsibilities of research staff. Researchers have difficulty in setting priorities and their professional identities can fluctuate because the focus of the museum itself has changed. While researchers are sufficiently aware of the museum's need to raise funds, and take visitors' interests into account, they are dissatisfied with the conflicting presumptions: museums are forced to simultaneously follow the model of the leisure industry and are expected to provide reliable expertise. 
On the basis of empirical material collected from five national museums in four neighbouring countries (Estonia, Latvia, Lithuania, Finland), the study explains how researchers in this region interpret their responsibilities and how role conflict and role ambiguity manifest themselves in their professional identity. For this purpose, the study focused on researchers' statements about their perceived professional status, enabling the study to follow their subjective views.

In most cases, museum researchers act as collection keepers and mediators, in the role of experts, but stay away from academic research. In cases where academic work is emphasised, the study of collections has become more secondary (for example at the ERM). The data on which this study is based show that the identity of the museum researcher has experienced less changes at Lithuania's NML in recent years and is therefore perceived as being less conflicted and ambiguous as elsewhere. The changes mainly concern the Estonian, Latvian and Finnish museums studied. The sharpest contradictions within the position of researcher, and the researchers' identity conflicts, were noticeable in the museums of Estonia and Finland. One cause could be the stronger and more rapid development of their fields of communication, in which the dominance of marketisation affects and the demands upon the researchers can clearly be seen. The problem is that tasks for research staff have increased, but the power to influence the museum's goals and direction has decreased. This practice has caused internal conflict and insecurity among research staff.

Although each museum has peculiarities in the administrative organisation of research, the common denominator is the contradictory position of the researcher, which manifests itself in two discursive ways: 1) In museums where academic achievements are emphasised, role conflict has arisen because curating exhibitions and other mediation activities do not qualify as research, although there is a perceived expectation that they make the museum socially relevant and earn revenue. Accordingly, researchers' internal conflict is caused by the need to popularise, exhibit and advise on the one hand, and the underestimation of the same factors in the researcher's contribution on the other; 2) The second discourse showed that while accessing and servicing collections is a priority for the museum, research has become insignificant in the institution's plans. Controversially, the museum mediation activities presuppose the existence of basic research.

The study outlines how museum researchers define themselves primarily in comparison with academic professionals. Researchers valued their contributions to the museum's goals from a professional standpoint: the reflection of research goals in the museum's development plans and resources are of primary importance to them. Consequently, researchers pay great attention to the ability to carry out their tasks with professional thoroughness. They want to keep their output reliable.

Contrary to the widely held view that there is a conflict between the protection and presentation of collections to the public, this study shows the intrinsic contradiction lies elsewhere. The main problem is the gap that prevails in reconciling research with the specifics of the museum. Looking at the museum's relevance to society, applied research is increasingly preferred. But often this work is underrated compared to academic work both inside and outside the institution. In this context there is a gap between academic ambition (sometimes institutional, sometimes personal) and the need to sell services.

When institutional change occurs, employees enter a transitional identity phase. 
In order to align institutional and individual objectives and cope more successfully with the changed circumstances, they need more management support (Billot 2010). If an institution becomes more aware of employees' perceptions and sets either goals or evaluation criteria, the two sides can work together to find ways for employees to adapt their identities to reality in order to reconcile the goals of the institution and the individual. The position of research and the identity of the researcher in the museum largely depend on how the knowledge-based mediating activities are valued within museum and society. This requires a complex assessment of this role at the museum management level - neither exhibition nor advice can exist in isolation from research.

These arguments could be important starting points for the institution when organising its work and designing the role of researcher. Cultural policy makers could also learn from this if they want museums to remain important to society in the field of education and culture, because prioritising mercantile goals does not provide a sustainable foundation. The museum risks losing its credibility in society if researchers become insecure or demotivated, or refuse to contribute to the museum's goals. In contrast, for museums researchers to fulfil their potential they must be able to provide knowledgebased interpretations and generalisations about museum themes and collections. Thus, researchers are not motivated if they are reduced to a service-oriented workforce. Their potential would be used more effectively if the institution recognised the possibility that academic research can adapt to the specifics of museum research.

\section{NOTES}

1 The international Research and Museums symposium was held at the Royal Swedish Academy of Science in Stockholm in May 2007, the organisers were the Nationalmuseum and the Nobel Museum (see proceedings: Cavalli-Björkman and Lindqvist 2008). The Exhibition as Product and Generator of Scholarship conference was held at the Deutsches Museum in Munich in November 2008 (see proceedings: Lehmann-Brauns et al. 2010). The Cultures of Curating: Curatorial Practices and the Production of Meaning, 1650-2000 conference was held at the University of Lincoln in July 2012 (see conference papers: Longair 2015).

2 Discussions about the challenges of the museum researcher's profession started to attract interest in the Estonian museum field in the 2010s, due to the state's research policy; it was at this time that the power of the market economy over science and higher education began to increase. Problems with museum research were discussed at the annual conferences of Estonian museums in 2010 and 2011. In these (mainly verbal) discussions the underfunding of research was highlighted, as were museum research as a science, and the researcher's title and responsibilities. There is consensus in the Estonian museum field that research in museums is and must be at the service of exhibitions and education. This was advocated in the Exhibitions Versus Science? Dilemmas, Searches and Solutions conference held in April 2018 at the Estonian National Museum, Tartu.

3 The position of the museum researcher is titled 'curator' in English-speaking countries, although 'researcher' or 'researcher-curator' are also options. The term 'curator' is also used to refer to a museum or gallery exhibition officer; often the curator performs the role of exhibition curator (see Ruge 2008: 22).

4 Only three interviewed researchers had work experience of just under ten years, most had 15-25 and more years. This may indicate that the museum is a place to work for a long time, or that those with more experience were more willing to give interviews. 
5 The results could be influenced by the language of the interviews: the only one of the studied museum's languages I speak is Estonian. The languages I used in Latvia, Lithuania and Finland were Russian and English. Both the need to speak in a foreign language and the brief time to become acquainted with the interviewees negatively affected the interviewees' spontaneity in expressing their thoughts and made them use shorter or simpler expressions. I used my mother tongue in the Estonian interviews.

6 For example, Swedish museologist Kerstin Smeds (2018: 155) suggests there are paradigmatic reasons why museums are still not sufficiently accessible: "departments of collection, and those of communication and exhibition, most often work according to entirely different paradigms and traditions".

7 Although museums often have extensive archives of photographs, videos and manuscripts, the literature emphasises the need for object-based research because of the risk of losing expertise on objects and materials (see Conn 2010; Lehmann-Brauns et al. 2010; Thomas 2016). One reason may be that the use of pictorial and written archives by historians is more common, while the use of objects as a source requires additional knowledge and skills.

8 The application of the 'exhibition as research' method (Bjerregaard 2019) in the preparation of the ENM's two permanent exhibitions Encounters, and Echo of the Urals, which opened in 2016 can be mentioned in my opinion, although the interviewees themselves did not point to such an approach.

9 During the interviews, the Food Heritage Studies project (see ENM b) was conducted at ERM. This project was a positive example of bringing the potential of collections to society in a more varied way than online. Within the project, the objects and archives were researched and articles and sources were published, thus introducing the value of the collections primarily to local food producers by helping them design their products, both in terms of content and packaging.

10 One objective reason why research based on collections is not a priority at the ENM could be the composition of the collections. The ENM does not have collections of subject-specific disciplines, such as numismatics or archeology, while they do exist in other museums. The main content of ERM's collections is ethnographic, a suitable source for studying Estonian peasant culture from the 19th century to the beginning of the 20th century. Today, although artefacts from the second half of the 20th century and modern material culture need to be collected and studied, the focus of the research has shifted (away from 'old' collections).

\section{SOURCES}

$\mathrm{FM}=$ Author's fieldwork materials

This study, in accordance with EU and Tartu University codes of ethics, protected interviewee anonymity. The interviewees are coded, first by museum acronym and then by a single alphabetical letter (for example EHM A). The list of interviewees, interview recordings, and transcriptions are in the possession of the author.

\section{REFERENCES}

Alberti, Samuel J. M. M. 2012. The Status of Museums. - Geographies of Nineteenth-Century Science, edited by David N. Livingstone and Charles W. J. Withers. Chicago, IL: University of Chicago Press, 51-72. 
Anderson, Robert G. W. 2005. To Thrive or Survive? The State and Status of Research in Museums. - Museum Management and Curatorship 20 (4): 297-311. DOI: https://doi. org/10.1080/09647770500602004.

Arnold, Ken. 2016. Thinking Things Through: Reviving Museum Research. - Science Museum and Research 5. DOI: https://doi.org/10.15180/160505.

Bennett, Tony. 1995. The Birth of the Museum. London: Routledge.

Billot, Jennie. 2010. The Imagined and the Real: Identifying the Tensions for Academic Identity. - Higher Education Research and Development 29 (6): 709-721. DOI: https://doi.org/10.1080/0729 4360.2010.487201.

Bjerregaard, Peter, ed. 2019. Exhibitions as Research: Experimental Methods in Museums. London: Routledge. DOI: https://doi.org/10.4324/9781315627779.

Brüning, Jochen. 2010. Exhibitions vs. Publications: On Scientific Achievements and Their Evaluation. - The Exhibition as Product and Generator of Scholarship, edited by Susanne LehmannBrauns, Christian Sichau and Helmuth Trischler. Berlin: Max Planck Institute for the History of Science, 25-28.

Campbell, Steven. 2018. Role Theory, Foreign Policy Advisers, and U.S. Foreign Policymaking. International Journal of Social Sciences 59 (1): 43-55.

Cavalli-Björkman, Görel and Svante Lindqvist, eds. 2008. Research and Museums. Proceedings of an International Symposium in Stockholm 22-25 May 2007. Archives of the Nobel Museum 11. Stockholm: Nationalmuseum.

Clifton-Ross, Jaime; Ann Dale and Robert Newell. 2019. Frameworks and Models for Disseminating Curated Research Outcomes to the Public. - SAGE Open 9 (2): 1-13. DOI: https://doi. org/10.1177/2158244019840112.

Conn, Steven. 2010. Do Museums Still Need Objects? Philadelphia, PA: University of Pennsylvania Press. DOI: https://doi.org/10.9783/9780812201659.

Cross, Sally and Helen Wilkinson. 2007. Making Collections Effective. Effective Collections: An Introduction. Collections for the Future: Two Years on. London: Museums Association. https://www. museumsassociation.org/download?id=14112 (accessed May 21, 2020).

Czarniawska, Barbara. 2012. Organization Theory Meets Anthropology: A Story of an Encounter. - Journal of Business Anthropology 1 (1): 118-140. DOI: https://doi.org/10.22439/jba.v1i1.3549.

Desvallées, André and François Mairesse, eds. 2010. Key Concepts of Museology. Paris: Armand Collin.

Doyle, Alison. 2019. Museum Curator Skills List and Examples. - Balancecareers. https://www. thebalancecareers.com/museum-curator-skills-2062439 (accessed May 21, 2020).

Edson, Gary and David Dean. 1996. The Handbook for Museums. London: Routledge.

Edwards, Elise Coralie. 2007. The Future for Curators. - Papers from the Institute of Archaeology 18 (S1): 98-114. DOI: https://doi.org/10.5334/pia.290.

ENM a. Research. - Estonian National Museum. https://www.erm.ee/en/content/research (accessed May 20, 2020).

ENM b. Food Heritage Studies project. - Estonian National Museum. https://www.erm.ee/en/content/food-heritage-studies (accessed May 20, 2020).

Fägerborg, Eva. 2006. Samdok: From Innovation to Integration. Conference paper presented at CIDOC 06, Gothenburg, Sweden, September 10-14, 2006. - CIDOC. http://cidoc.mini.icom. museum/wp-content/uploads/sites/6/2018/12/Fagerborg_Eva.pdf (accessed November 3, 2020).

Foley, Malcolm and Gayle McPherson. 2000. Museums as Leisure. - International Journal of Heritage Studies 6 (2): 161-174. DOI: https://doi.org/10.1080/135272500404205.

Geijsel, Femke and Frans Meijers. 2005. Identity Learning: The Core Process of Educational Change. - Educational Studies 31 (4): 419-430. DOI: https://doi.org/10.1080/03055690500237488. 
Geoghegan, Hillary and Alison Hess. 2015. Object-Love at the Science Museum: Cultural Geographies of Museum Storerooms. - Cultural Geographies 22 (2): 445-465. DOI: https://doi. org/10.1177/1474474014539247.

Glaister, Jane and Helen Wilkinson. 2005. Collections for the Future. Report of a Museums Association. London: Museums Association. https://www.museumsassociation.org/download?id=11121 (accessed May 21, 2020).

Graham, Mark S. 2005. Assessing Priorities: Research at Museums. - Museum Management and Curatorship 20 (4): 287-291. DOI: https://doi.org/10.1080/09647770500402004.

Greene, Candace S. 2015. Museum Anthropology. - Emerging Trends in the Social and Behavioral Sciences: An Interdisciplinary, Searchable, and Linkable Resource, edited by Robert Scott and Stephen Kosslyn. Hoboken, NJ: John Wiley \& Sons, 1-15. DOI: https://doi.org/10.1002/9781118900772. etrds0105.

Griffin, Des and Morris Abraham. 2000. The Effective Management of Museums: Cohesive Leadership and Visitor-Focused Public Programming. - Museum Management and Curatorship 18 (4): 335-368. DOI: https://doi.org/10.1080/09647770000301804.

Hakamies, Inkeri. 2017. Practice Makes 'Museum People'. - Museum and Society 15 (2): 142-152. DOI: https://doi.org/10.29311/mas.v15i2.829.

Hauser, Walter. 2010. Exhibition Making as Knowledge Production, or: Struggling with Artefacts, Visuals and Topographies. - The Exhibition as Product and Generator of Scholarship, edited by Susanne Lehmann-Brauns, Christian Sichau and Helmuth Trischler. Berlin: Max Planck Institute for the History of Science, 49-58.

Hood, Adrienne D. 2009. Material Culture: The Object. - History Beyond the Text. Routledge Guides to Using Historical Sources, edited by Sarah Barber and Corinna M. Peniston-Bird. New York, NY: Routledge, 294-334.

Jensen, Susanne Krogh. 2019. What a Curator Needs to Know: The Development of Professional Museum Work and the Skills Required in Danish Museums 1964-2018. - Museum Management and Curatorship 34 (5): 468-485. DOI: https://doi.org/10.1080/09647775.2019.1641832.

Kahn, Robert L.; Donald M. Wolfe, Robert P. Quinn, J. Diedrik Snoek and Robert A. Rosenthal. 1964. Organizational Stress: Studies in Roleconflict and Ambiguity. New York, NY: Wiley.

Keene, Suzanne. 2005. Fragments of the World: Uses of Museum Collections. Oxford: Elsevier Butterworth Heinemann. DOI: https://doi.org/10.4324/9780080456416.

Keene, Suzanne. 2008. Collections for People: Museums' Stored Collections as a Public Resource. London: University College London Institute of Archaeology.

Ladkin, Nicola. 2004. Collections Management. - Running a Museum: A Practical Handbook, edited by Patric J. Boylan. Paris: International Council of Museums, 17-30.

Lehmann-Brauns, Susanne; Christian Sichau and Helmuth Trischler, eds. 2010. The Exhibition as Product and Generator of Scholarship. Berlin: Max Planck Institute for the History of Science.

Longair, Sarah. 2015. Cultures of Curating: The Limits of Authority. - Museum History Journal 8 (1): 1-7. DOI: https://doi.org/10.1179/1936981614Z.00000000043.

Macdonald, Sharon. 1998. Exhibitions of Power and Powers of Exhibition: An Introduction to the Politics of Display. - The Politics of Display: Museums, Science, Culture, edited by Sharon Macdonald. London; New York, NY: Routledge, 1-24. DOI: https://doi.org/10.29311/mas. v16i2.2788.

Macdonald, Sharon; Christine Gerbich and Margareta von Oswald. 2018. No Museum Is an Island: Ethnography beyond Methodological Containerism. - Museum and Society 16 (2): 138-156.

Matassa, Freda. 2010. Active Collections: Re-Visiting Our Collection for More and Better Use. - Encouraging Collections Mobility: A Way Forward for Museums in Europe, edited by Susanna Pettersson, Monika Hagedorn-Saupe, Teijamari Jyrkkiö and Astrid Weij. Helsinki: Finnish National Gallery, 107-135. 
McCall, Vikki and Clive Gray. 2014. Museums and the 'New Museology': Theory, Practice and Organisational Change. - Museum Management and Curatorship 29 (1): 19-35. DOI: https://doi. org/10.1080/09647775.2013.869852.

McPherson, Gayle. 2006. Public Memories and Private Tastes: The Shifting Definitions of Museums and Their Visitors in the UK. - Museum Management and Curatorship 21 (1): 44-57. DOI: https://doi.org/10.1080/09647770600602101.

Morse, Nuala; Rex Bethany and Sarah Harvey Richardson. 2018. Editorial: Methodologies for Researching the Museum as Organization. - Museum and Society (Special Issue: Methodologies for Researching the Museum as Organization) 16 (2): 112-122. DOI: https://doi.org/10.29311/mas. v16i2.2810.

Nielsen, Jane K. 2014. Transformations in the Postmodern Museum. - Museological Review 18: $22-29$.

Nielsen, Jane K. 2015. The Relevant Museum: Defining Relevance in Museological Practices. Museum Management and Curatorship 30 (5): 364-378. DOI: https://doi.org/10.1080/09647775.2 015.1043330.

Olssen, Mark and Michael A. Peters. 2005. Neoliberalism, Higher Education and the Knowledge Economy: From the Free Market to Knowledge Capitalism. - Journal of Education Policy 20 (3): 313-345. DOI: https://doi.org/10.1080/02680930500108718.

Osborne, Stephen P. 2006. The New Public Governance? - Public Management Review 8 (3): 377387. DOI: https://doi.org/10.1080/14719030600853022.

Reid, Monty and Bruce Naylor. 2005. ThreeReasons to Worry AboutMuseum Researchers. - Museum Management and Curatorship 20 (4): 359-364. DOI: https://doi.org/10.1080/09647770501002004.

Reidla, Jana. 2018. Curators With and Without Collections: A Comparative Study of Changes in the Curator's Work at National Museums in Finland and in the Baltic States. - Journal of Ethnology and Folkloristics 12 (2): 115-138. DOI: 10.2478/jef-2018-0014.

Ruge, Angelika, ed. 2008. Museum Professions: A European Frame of Reference. http://ictop.org/ wp-content/uploads/2019/06/ICTOP-Museum-Profession_frame_of_reference_2008.pdf (accessed May 21, 2020).

Saayman, Tamsen and Anne Crafford. 2011. Negotiating Work Identity. - SA Journal of Industrial Psychology 37 (1): 1-12. DOI: https://doi.org/10.4102/sajip.v37i1.963.

Schertz, Peter J. 2015. The Curator as Scholar and Public Spokesperson. - Journal of Eastern Mediterranean Archaeology \& Heritage Studies 3 (3): 277-282. DOI: https://doi.org/10.5325/jeasmedarcherstu.3.3.0277.

Schmidt, Susanne; Ulrike Roesler, Talin Kusserow and Renate Rau. 2014. Uncertainty in the Workplace: Examining Role Ambiguity and Role Conflict, and Their Link to Depression - A Meta-Analysis. - European Journal of Work and Organizational Psychology 23 (1): 91-106. DOI: https://doi.org/10.1080/1359432X.2012.711523.

Schnalke, Thomas. 2010. Arguing with Objects: The Exhibition as a Scientific Format of Publication. - The Exhibition as Product and Generator of Scholarship, edited by Susanne LehmannBrauns, Christian Sichau and Helmuth Trischler. Berlin: Max Planck Institute for the History of Science, 103-110.

Smeds, Kerstin. 2018. Museum Science? Museological Shortcuts. - Nordisk Museologi 1: 154-156. DOI: https://doi.org/10.5617/nm.6416.

TartgetJobs. 2019. Curator: Job description. - Target Jobs. https://targetjobs.co.uk/careers-advice/ job-descriptions/279189-curator-job-description (accessed May 21, 2020).

Thomas, Nicholas. 2010. The Museum as Method. - Museum Anthropology 33 (1): 6-10. DOI: https://doi.org/10.1111/j.1548-1379.2010.01070.x.

Thomas, Nicholas. 2016. The Return of Curiosity: What Museums Are Good for in the 21st Century. London: Reaktion Books. 
Thomson, Kerstin; Mikael Holmgren Caicedo and Maria Mårtensson. 2014. The Quest for Public Value in the Swedish Museum Transition. - Public Value Management, Measurement and Reporting. Studies in Public and Non-Profit Governance 3, edited by James Guthrie, Giuseppe Marcon, Salvatore Russo and Federica Farneti. Bingley: Emerald Group Publishing, 105-128. DOI: https://doi.org/10.1108/S2051-663020140000003005.

Tlili, Anwar. 2014. Managing Performance in Publicly Funded Museums in England: Effects, Resistances and Revisions. - International Journal of Heritage Studies 20 (2): 157-180. DOI: https://doi.org/10.1080/13527258.2012.737354.

Ughetto, Pascal. 2017. Scholars and Poor Communicators? Old Masters Exhibitions as a Scientific Practice and Communication Activity for Art Museum Curators. - Current Sociology 65 (3): 376-394. DOI: https://doi.org/10.1177/0011392115617226.

Vergo, Peter, ed. 1989. The New Museology. London: Reaktion Books.

Weil, Stephen E. 1999. From Being About Something to Being For Somebody: The Ongoing Transformation of the American Museum. - Daedalus 128 (3): 229-258. https://www.jstor.org/stable/20027573 (accessed November 3, 2020).

Wickham, Mark and Melissa Parker. 2007. Reconceptualising Organisational Role Theory for Contemporary Organisational Contexts. - Journal of Managerial Psychology 22 (5): 440-464. DOI: https://doi.org/10.1108/02683940710757182.

Wood, Barbara. 2019. Who Holds Power in Heritage and What Does That Mean for Museums? Museological Review 23: 15-24.

Ylijoki, Oili-Helena and Jani Ursin. 2013. The Construction of Academic Identity in the Changes of Finnish Higher Education. - Studies in Higher Education 38 (8): 1135-1149. https://doi.org/1 0.1080/03075079.2013.833036. 